\title{
Detection Problems Associated to Processed Food Allergens
}

\section{Silvia M. Albillos*}

INBIOTEC (Institute of Biotechnology of León) Av. del Real n 1, 24006, León, Spain

\section{The Food Allergen Labeling Mandate}

Do we really count on accurate technologies for allergen detection? Good food allergen detection methods are vital for many food manufacturers if they want to avoid expensive food product recalls, as well as for food protection agencies all over the world, in order to achieve their goal which is to assure the safety of consumers. Actual food labeling legislation include the European Labeling Directive (Council Directive 2000/13/EC) amended in Directives 2003/89/EC and 2007/68/EC, the Australia New Zealand Food Standards Code of 2002, reviewed in 2007 in the Allergen Management and Labeling Guide, the Food Allergen Labeling Consumer Protection Act of 2004 in the US (also known as FALCPA) and the Food and Drug Regulations of Canada, amended in 2008 for enhanced labeling of food allergens. All of them oblige food producers and manufacturers to indicate the presence of allergens in their products. This enforcement carries along some consequences, such as that many food companies, in order to be on the safe side, label food indiscriminately or abuse the "may contain" statement with a considerable reduction of the variety of food products the regular consumer can purchase [1].

On the other hand, it is somehow paradoxical, that food protection agencies indicate that allergens are to be detected, but don't risk in establishing valid threshold limits or action levels for allergens in food commodities. This position is quite understandable, as allergic reactions are very different from one person to another, and the lower limit that elicits a systemic response is also different. In terms of allergen quantitation, the scientific community has reached a sort of dead end until agreed thresholds are established. Nevertheless, some attempts have been done in order to indicate how much is too much by means of risk assessment methodologies $[2,3]$.

Researchers have to face the challenge of studying the effect of food processing on the structure and allergenic properties of food allergens and obtaining detection procedures that can overcome the problems associated to food allergen extraction from complex matrices followed by accurate detection. OMICS group, and its Journal of Food Processing and Technology in periodical issues emphasize the importance of the study of food processing and this is a most relevant topic for the field of food allergen research.

\section{Can We Assume That Food Allergen Fast Quantitation Methods Are Accurate?}

Most of the commercially available food allergen detection methods, either qualitative or quantitative, use some kind of antibody as a probe that specifically binds to the allergen and as a result generates a signal that can be detected visually, by fluorescence or by means of a spectrophotometer (ELISAs and lateral flow devices among others). On many occasions, these methods are portable, and can be used in house near the production lines in the industry by trained personnel but without extremely high qualification. Some other detection methods are based on DNA for allergen identification, but as the presence of the gene does not guarantee the presence of the expressed protein, they are not so commonly used for practical applications and besides, they require higher qualification of the analyst.

The question at this point is whether these immunological analytical tests are valid for allergen identification or quantitation once food has been processed, which on the other hand, is the most frequent scenario for food commodities or for contact surfaces in the facilities. The bad news is that, as the fore mentioned methods rely on extracted protein (or antigen) from the sample, on many occasions these methods gravely underestimate the presence of tested allergens in processed food. The main reason is reduced protein solubility after food processing due to protein aggregation or chemical reactions with other macromolecules that render poor recovery due to the complexity of the food matrix itself [4]. This causes dangerous false negatives that could end up in expensive food recalls or, in the worst-case scenario, in fatalities.

It is well known that proteins unfold or denature upon thermal treatment, and more studies are required in the future in order to understand the effect on native protein structure of the novel emerging food processing procedures, such as high pressure, pulsed UV irradiation, microwave processing, infrared heating, ozone, cold plasma and so on. The performance of actual detection methods for these types of samples is still to be confirmed, but in comparison with what happens to allergens in thermally processed samples, it can be expected that they will have shortcomings as well. On the other hand, more powerful detection methods such as HPLC or UPLC couplet to MS have proven better efficacy in quantifying low detection levels of food allergens, but still with important levels of underestimation $[4,5]$. These techniques are not at hand to most of the people due to the elevated costs of the equipment needed and requirements of high qualification and expertise on the part of the analyst.

The establishment of threshold values requires supporting analytical methodologies to enforce and comply with the actual regulations [5] and yet, fast, simple, accurate, reproducible and sensitive assay methods are still demanded by all players involved in this problem of growing concern to the global population.

\section{References}

1. Zurzolo GA, Mathai ML, Koplin JJ, Allen KJ (2012) Hidden allergens in foods and implications for labelling and clinical care of food allergic patients. Curr Allergy Asthma Rep.

*Corresponding author: Silvia M. Albillos, INBIOTEC (Institute of Biotechnology of León) Av. del Real n1, 24006, León, Spain, E-mail: silvia.albillos@gmail.com

Received April 25, 2012; Accepted June 27, 2012; Published June 29, 2012

Citation: Albillos SM (2012) Detection Problems Associated to Processed Food Allergens. J Food Process Technol 3:e104. doi:10.4172/2157-7110.1000e104

Copyright: () 2012 Albillos SM. This is an open-access article distributed under the terms of the Creative Commons Attribution License, which permits unrestricted use, distribution, and reproduction in any medium, provided the original author and source are credited. 
Citation: Albillos SM (2012) Detection Problems Associated to Processed Food Allergens. J Food Process Technol 3:e104. doi:10.4172/2157$7110.1000 \mathrm{e} 104$

2. Taylor SL, Hefle SL, Bindslev-Jensen C, Atkins FM, Andre C, et al. (2004) A consensus protocol for the determination of the threshold doses for allergenic foods: how much is too much? Clin Exp Allergy 34: 689-695.

3. Madsen CB, Hattersley S, Allen KJ, Beyer K, Chan CH, et al. (2012) Can we define a tolerable level of risk in food allergy? Report from a EuroPrevall/UK Food Standards Agency workshop. Clin Exp Allergy 42: 30-37.
4. Newsome GA, Scholl PF (2012) Quantification of allergenic bovine milk $\alpha(s 1)$ casein in baked goods using an intact (15)N-labeled protein internal standard. J Agric Food Chem.

5. Diaz-Amigo C, Popping B (2010) Analytical testing as a tool for the enforcement of future regulatory thresholds for food allergens. J AOAC Int 93: 434-441. 